\title{
Editorial: The Role of Complement in Tumors
}

\author{
Barbara E. Rolfe ${ }^{1 *}$, Ruben Pio $^{2}$, Trent M. Woodruff ${ }^{3}$, Maciej M. Markiewski ${ }^{4}$ and \\ Helga D. Manthey ${ }^{1}$ \\ ${ }^{1}$ Australian Institute for Bioengineering and Nanotechnology, The University of Queensland, Brisbane, QLD, Australia, \\ ${ }^{2}$ Center for Applied Medical Research (CIMA), University of Navarra, Pamplona, Spain, ${ }^{3}$ School of Biomedical Sciences, The \\ University of Queensland, Brisbane, QLD, Australia, ${ }^{4}$ Department of Immunotherapeutics and Biotechnology, School of \\ Pharmacy, Texas Tech University Health Sciences Center, Abilene, TX, United States
}

Keywords: complement, cancer, metastasis, C5b-9, C1q, C3a, C5a, complement regulatory proteins

\section{Editorial on the Research Topic}

\section{The Role of Complement in Tumors}

Activation of the complement system is one of the earliest responses to invading pathogens and tissue damage (1). Complement activation leads to production of a range of effectors including the opsonin C3b, the anaphylatoxins C3a and C5a, and the C5b-9 complex (membrane attack complex; MAC) $(2,3)$. In addition to potent innate immune activities, complement effector systems also contribute to efficient adaptive immune responses (4). While critical to proper immune function, inappropriate or excessive complement activation contributes to many pathological inflammatory

OPEN ACCESS

Edited and reviewed by: Catherine Sautes-Fridman, INSERM U1138 Centre de Recherche des Cordeliers, France

*Correspondence: Barbara E. Rolfe b.rolfe@uq.edu.au

Specialty section:

This article was submitted to Cancer Immunity and Immunotherapy, a section of the journal Frontiers in Immunology

Received: 14 January 2020 Accepted: 20 January 2020 Published: 11 February 2020

Citation:

Rolfe BE, Pio R, Woodruff TM, Markiewski MM and Manthey $H D$ (2020) Editorial: The Role of

Complement in Tumors.

Front. Immunol. 11:139. doi: 10.3389/fimmu.2020.00139 conditions (5), including cancer. As described in this issue, the complement system is increasingly recognized as a double-edged sword: on the one hand contributing to the anti-tumor response, but on the other protecting the tumor against immune attack and promoting metastasis.

\section{COMPLEMENT-DEPENDENT CYTOTOXICITY AND C5b-9 (MEMBRANE ATTACK COMPLEX)}

As described by Macor et al., the complement system has long been recognized to contribute to anti-tumor defense mechanisms via complement dependent cytotoxicity (CDC) (6) and antibodydependent cell mediated cytotoxicity (ADCC) (7). The introduction of recombinant antibodies for cancer treatment has led to renewed interest in complement as an anti-tumor defense system. The protective role of complement in cancer is discussed, with focus on the beneficial effect of complement-fixing antibodies which initiate cancer cell killing via CDC.

The cytotoxic activities of C5b-9, and the mechanisms by which it damages cancer cells, are further discussed by Fishelson and Kirschfink, along with the multiple mechanisms that tumor cells employ to resist C5b-9-induced death. They discuss the potential for therapeutic approaches to counter tumor escape mechanisms and potentiate antibody-based immunotherapies, but caution that intervention strategies to augment complement activation could also worsen outcomes.

Although C5b-9 has traditionally been attributed an anti-tumoral role through CDC, Vlaicu et al. review the evidence that C5b-9 at a sub-lytic dose stimulates tumor growth. Hence strategies to counteract the tumor-promoting traits of C5b-9 and potentiate anti-tumoral actions (including enhanced efficacy of antibody-based immunotherapy) may be the next major direction for immuno-oncology. 


\section{COMPLEMENT REGULATORY PROTEINS}

As described by Geller and Yan, membrane and soluble complement regulatory proteins (CRPs) prevent excessive complement activation. Therefore, over-expression of CRPs by tumor cells protects them against complement-mediated attack, interferes with anti-tumor therapies, and enhances metastatic potential. The application of CRPs as prognostic biomarkers and therapeutic targets is discussed, along with the potential for combinatorial approaches with other anti-tumor therapies.

\section{COMPLEMENT C1q}

The first subcomponent of the classical complement pathway, $\mathrm{C} 1 \mathrm{q}$ is a pattern recognition molecule locally synthesized by macrophages and dendritic cells (8). Bioinformatics analysis by Mangogna et al. suggests $\mathrm{Clq}$ as a new prognostic biomarker for several cancers.

\section{ANAPHYLATOXINS C3a AND C5a}

Since the seminal paper of Markiewski et al. (9) identifying a role for $\mathrm{C} 5 \mathrm{a}$ in promoting tumor progression, similar effects have been demonstrated in a range of murine cancer models. Wang et al. propose C3aR and C5aR1 as a new class of immune checkpoints. They discuss findings suggesting that $\mathrm{C} 3 \mathrm{aR} / \mathrm{C} 5 \mathrm{aR}$ signaling regulates $\mathrm{T}$ cell mediated antitumor immunity via transcriptional suppression of interleukin (IL)10. Given resistance of the majority of patients to the current forms of immunotherapy, and adverse reactions associated with these approaches, the authors suggest the manipulation of the C3aR/C5aR/IL-10 pathway as an alternative strategy for cancer.

Lenkiewicz et al. discovered that C3 and C5 cleavage fragments enhance trafficking, motility and, therefore, dissemination of malignant cells in hematologic malignancies through a p38 MAPK and inducible heme oxygenase 1 (HO-1) manner. They propose that activation of the complement cascade in patients with these malignancies (e.g., triggered by infection) can contribute to faster dissemination of disease. Thus, targeting this pathway may ameliorate dissemination of leukemic cells and improve clinical outcomes in these patients.

Kleczko et al. discuss the potential for complement targeting therapies for the treatment of intractable cancers, in particular lung cancer. They review the mechanisms by which the anaphylatoxins C3a and C5a influence tumor growth and promote epithelial-mesenchymal transition and tumor metastasis. Since complement proteins can regulate both proand anti-tumorigenic pathways, the authors stress the need to better understand the effects of complement activation within tumor tissue, and how this may be influenced by different oncogenic drivers.

Cancer metastasis is estimated to be responsible for greater than $90 \%$ of cancer deaths (10). As discussed by Ajona et al., distorted complement homeostasis not only remodels the tumor microenvironment by inhibiting anti-tumor immune responses, but is also crucial to metastasis, endowing tumor cells with properties required for metastatic dissemination and establishment. Complement activation products (primarily C3a and C5a) induce a range of mediators which promote epithelialmesenchymal transition, tumor growth, invasion, dissemination via lymphatic and circulatory systems, and also protect cells within the metastatic niche. The authors highlight the potential of complement-targeting drugs to augment the clinical efficacy of current immunotherapies and effectively eradicate both primary tumors and distant metastases.

\section{CONCLUSIONS}

Despite recent clinical advances in cancer immunotherapy, the estimated percentage of patients responding to checkpoint inhibitors in the United States in 2018 was only $12.46 \%$ (11). Hence there remains an urgent need for novel therapeutic strategies to boost response rates. As a critical link between the innate and adaptive immune systems, the complement system is a promising therapeutic target. However, knowledge is the key to realizing the clinical potential of complementtargeting therapeutics. Only a thorough understanding of the role of complement pathways in the tumor microenvironment will enable development of strategies to selectively (and safely) target the pro-tumor effects of complement, while simultaneously augmenting the anti-tumor effects. To quote Fishelson and Kirschfink, "currently we perceive only the tip of the ice-berg of ... interactions between cancer cells and complement components." Indeed, given the diversity of responses, therapeutic protocols will likely need to be optimized for each cancer type and stage, and possibly for individual cancer patients, depending on their "immune history."

\section{AUTHOR CONTRIBUTIONS}

All authors contributed to the conception and design of this work. BR drafted the manuscript, the other editors RP, TW, $\mathrm{MM}$, and HM provided critical revisions and approved the submitted manuscript.

\section{FUNDING}

$\mathrm{BR}, \mathrm{RP}, \mathrm{TW}$, and $\mathrm{HM}$ acknowledge support from grants from the Australian National Health and Medical Research Council (NHMRC; APP1103951 and APP1164202) and Cancer Council Queensland (CCQ). RP was supported by the AECC Scientific Foundation, and Fondo de Investigación SanitariaFondo Europeo de Desarrollo Regional Una manera de hacer Europa (PI17/00411) and MM by the National Institute of Health (R01CA190209).

\section{ACKNOWLEDGMENTS}

We thank all the authors for their contributions to this Research Topic. We also thank the reviewers for their evaluation of the manuscripts. 


\section{REFERENCES}

1. Kolev M, Kemper C. Keeping it all going-complement meets metabolism. Front Immunol. (2017) 8:1. doi: 10.3389/fimmu.2017.00001

2. Merle NS, Church SE, Fremeaux-Bacchi V, Roumenina LT. Complement system part I - Molecular mechanisms of activation and regulation. Front Immunol. (2015) 6:262. doi: 10.3389/fimmu.2015.00262

3. Merle NS, Noe R, Halbwachs-Mecarelli L, Fremeaux-Bacchi V, Roumenina LT. Complement system part II: role in immunity. Front Immunol. (2015) 6:257. doi: $10.3389 /$ fimmu.2015.00257

4. Clarke EV, Tenner AJ. Complement modulation of $\mathrm{T}$ cell immune responses during homeostasis and disease. J Leukoc Biol. (2014) 96:745-56. doi: 10.1189/jlb.3MR0214-109R

5. Hawksworth OA, Li XX, Coulthard LG, Wolvetang EJ, Woodruff TM. New concepts on the therapeutic control of complement anaphylatoxin receptors. Mol Immunol. (2017) 89:36-43. doi: 10.1016/j.molimm.2017.05.015

6. Ostrand-Rosenberg S. Cancer and complement. Nat Biotechnol. (2008) 26:1348-9. doi: 10.1038/nbt1208-1348

7. Gelderman KA, Tomlinson S, Ross GD, Gorter A. Complement function in mAb-mediated cancer immunotherapy. Trends Immunol. (2004) 25:158-64. doi: 10.1016/j.it.2004.01.008

8. Thielens NM, Tedesco F, Bohlson SS, Gaboriaud C, Tenner AJ. C1q: a fresh look upon an old molecule. Mol Immunol. (2017) 89:73-83. doi: 10.1016/j.molimm.2017.05.025
9. Markiewski MM, DeAngelis RA, Benencia F, Ricklin-Lichtsteiner SK, Koutoulaki A, Gerard C, et al. Modulation of the antitumor immune response by complement. Nat Immunol. (2008) 9:1225-35. doi: 10.1038/ ni. 1655

10. Chaffer CL, Weinberg RA. A perspective on cancer cell metastasis. Science. (2011) 331:1559-64. doi: 10.1126/science.12 03543

11. Haslam A, Prasad V. Estimation of the percentage of US patients with cancer who are eligible for and respond to checkpoint inhibitor immunotherapy drugs. JAMA Netw Open. (2019) 2:e192535. doi: 10.1001/jamanetworkopen.201 9.2535

Conflict of Interest: The authors declare that the research was conducted in the absence of any commercial or financial relationships that could be construed as a potential conflict of interest.

Copyright (c) 2020 Rolfe, Pio, Woodruff, Markiewski and Manthey. This is an openaccess article distributed under the terms of the Creative Commons Attribution License (CC BY). The use, distribution or reproduction in other forums is permitted, provided the original author(s) and the copyright owner(s) are credited and that the original publication in this journal is cited, in accordance with accepted academic practice. No use, distribution or reproduction is permitted which does not comply with these terms. 